\title{
Studies of Nickel Electrocrystallization on Platinum
}

\section{Ultramicroelectrodes}

\author{
A.N. Correia and S.A.S. Machado* \\ Instituto de Química de São Carlos, Universidade de São Paulo \\ C.P. 780, 13560-970 São Carlos - SP, Brazil
}

Received: April 30, 1996; November 5, 1996

\begin{abstract}
A eletrocristalização de níquel foi estudada sobre ultramicroeletrodo (UME) de platina. O comportamento dos transientes de corrente indicou um processo de nucleação instantânea sob controle cinético. A aplicação do modelo de Abyaneh mostrou que os núcleos crescem com uma geometria do tipo calota esférica, possuindo valores diferentes para as constantes de velocidade no sentido paralelo e perpendicular à superfície. As constantes de velocidade para o crescimento de núcleos no sentido paralelo variaram de $5,97 \times 10^{-7}$ a $1,92 \times 10^{-7} \mathrm{~mol} \mathrm{~cm}^{-2} \mathrm{~s}^{-1}$, com o aumento do potencial de $-0,57$ a $-0,63 \mathrm{~V}$, enquanto que as correspondentes constantes no sentido perpendicular apresentaram valores em torno de $1,44 \times 10^{-7} \mathrm{~mol} \mathrm{~cm}^{-2} \mathrm{~s}^{-1}$. As relações entre estas forneceram os ângulos de contato, cujos valores aumentaram de 27,5 a 87,6 graus. Finalmente, o número de núcleos formados aumentou com o potencial, de $0,43 \times 10^{7}$ a $379,09 \times 10^{7} \mathrm{~cm}^{-2}$.
\end{abstract}

The electrocrystallization of nickel was studied on a platinum ultramicroelectrode (UME). The behaviour of the current transients pointed to an instantaneous nucleation process under kinetic control. The application of Abyaneh's model showed that nuclei grow in a spherical cap geometry with different values for both rate constants in the parallel and perpendicular directions. The parallel rate constants for nuclei growth varied from $5.97 \times 10^{-7}$ to $1.92 \times 10^{-7} \mathrm{~mol}$ $\mathrm{cm}^{-2} \mathrm{~s}^{-1}$ by increasing the step potential from -0.57 to $-0.63 \mathrm{~V}$, while the perpendicular rate constant remained constant around $1.44 \times 10^{-7} \mathrm{~mol} \mathrm{~cm}^{-2} \mathrm{~s}^{-1}$. The relationships between these two constants give the contact angles of the crystallites, whose values also increased with potential from 27.5 to 87.6 degrees. Finally, the number of nuclei formed on the surface increased with potential from $0.43 \times 10^{7}$ to $379.09 \times 10^{7} \mathrm{~cm}^{-2}$.

Keywords: electrocrystallization, spherical caps, ultramicroelectrodes, nickel

\section{Introduction}

The initial stages in the electrodeposition of several metals onto different substrates frequently occur by the birth and three-dimensional growth of nuclei. During a short time interval after a potentiostatic pulse, applied to generate the nuclei, they grow free of interactions with neighbors. Within a such time domain, if the rate determining step is the diffusion of ions towards the surface, potentiostatic transients should present a linear dependence of the rising currents on $\mathrm{t}^{1 / 2}$ or t $^{2 / 3}$. The consequence of such a diffusion-controlled process is the formation of a number of perfectly spherical nuclei on the surface. A convenient model for describing such a process was developed by Hills et al. ${ }^{1-5}$ for either the instantaneous (i vs. $\mathrm{t}^{1 / 2}$ ) or the progressive $\left(\mathrm{i} v s . \mathrm{t}^{3 / 2}\right)$ birth of a large number of nuclei. This model was further generalized by Scharifker et al ${ }^{6-9}$ in a study of three-dimensional nucleation on a finite number of active sites followed by diffusion-controlled growth of nuclei. Those authors proposed that the current maxima in transients provide the information required to evaluate the density of active sites on the surface and the rate of nucleation per active site. Instantaneous or progressive nucleations are shown to be special cases of the generalized model. Milchev et al. ${ }^{10,11}$ studied the formation-dissolution equilibrium of nuclei at critical sizes. In the very initial time domain, the stability of newly-born nu- 
clei is highly dependent on experimental conditions. These authors have identified two distinct mechanisms of critical nucleus formation, namely: (i) by the direct attachment of ions from the electrolyte, or (ii) by surface diffusion of ad-atoms on the substrate.

In the absence of diffusion limitations, the characteristics of the nucleation process controlled by charge transfer are quite different. In order to analyze the nucleation growth controlled by electron transfer it is necessary to establish two different growth rates, one in the perpendicular and the other in the parallel direction in relation to the substrate. According to the values of these rate constants, the shape of the nuclei may vary from hemispherical (when both rate constants present the same value) to spherical cap (when the rate constant parallel to the surface is greater than the perpendicular one). A detailed model taking these special characteristics into account was developed by Abyaneh $^{12-16}$ in his studies of Ni nucleation. Fig. 1 presents the schematic model for the nucleation of a spherical-cap nucleus form ${ }^{16}$. In this figure, $v$ and $v$ ' represent speeds of growth parallel and perpendicular to the substrate respectively, $\mathrm{S}_{\mathrm{u}}$ is the actual flat area cut through by a slice $d y$ at a distance $y$ away from the substrate, and $\theta$ is the contact angle which defines the eccentricity of the spherical-cap. The author stated that for instantaneous nucleation:

(i) for short periods the current is proportional to the square of time and is given by:

$$
\mathrm{i}_{\text {small }(t)}=\frac{2+\cos \theta}{1+\cos \theta} \frac{z F \pi M^{2} k^{2} k^{\prime} N_{0}}{\rho^{2}} t^{2}
$$

where $\mathrm{z}$ is the number of electrons, $\mathrm{F}$ is the Faraday constant, $\mathrm{M}$ is the molar mass of the deposit, $\mathrm{k}$ and k' are the rate constants relative to parallel and perpendicular growth respectively, $N_{o}$ is the number of nuclei, $\rho$ is the density of the deposited species and $t$ is the time.

(ii) the current transient presents only one maximum before the steady-state is reached; and

(iii) the steady-state current value is obtained when $\mathrm{t} \rightarrow \infty$,

$\mathrm{i}_{t \rightarrow \infty} \rightarrow z F k^{\prime}$

For progressive nucleation, items (ii) and (iii) are also valid, but Eq. 1 changes to:

$$
\mathrm{i}_{\text {small }(t)} \cong \frac{2+\cos \theta}{1+\cos \theta} \frac{z F \pi M^{2} k^{2} k^{\prime} A}{3 \rho^{2}} t^{3}
$$

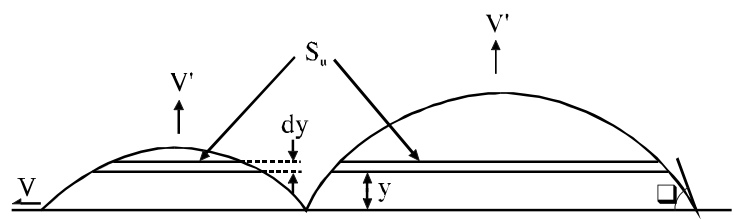

Figure 1. The nucleation of spherical cap growth forms ${ }^{16}$. with A being the nucleation rate. The general current-time equations in this model are:

$$
\begin{aligned}
& \mathrm{i}=2 z F k^{\prime} G_{i}(\tau) \text { for instantaneous nucleation } \\
& \mathrm{i}=3 z F k^{\prime} G_{p}(\tau) \text { for progressive nucleation }
\end{aligned}
$$

with the function $G(\tau)$, derived from the statistic of treatment adopted, being responsible for the unique maximum in the current transient.

The utilization of ultramicroelectrodes (UMEs) in electrocrystallization studies brought with it some novelties. UMEs are electrodes with at least one of their dimensions on the order of micrometers. Their small size is comparable to the thickness of the diffusion layer. Several advantages of such electrodes have already been described $^{17-20}$. Their characteristics can overcome some limitations in nucleation studies, for example: (a) all of the investigation methods used for electrocrystallization, such as chronoamperometry, suffer from theoretical and experimental uncertainties related to the lack of knowledge about the energy distribution on the non-ideal equipotential surface and (b) multiple nucleation presents questions related to overlap and interference. The progressive birth of nuclei implies a variation in crystallite sizes on the surface. Almost all of these uncertainties diminish when studies of multiple nucleation are carried out in electrodes with small dimensions. Moreover, UMEs constitute an adequate tool for the investigation of the birth and growth of a single nucleus.

Despite the advantages stated above, the use of UMEs presents brings some difficulties. A disk is the most useful UME shape, due to the facility in polishing the surface after each deposition. Nevertheless, diffusion towards the electrode surface is complicated because the edge of the disk electrolyzes the solution, preventing ions from reaching the center of the electrode. As a consequence, it is necessary to develop equations which properly describe the transient behavior. One attempt to do so was recently performed in our Laboratory ${ }^{21}$ with the aim of describing diffusion controlled nucleation process on a disk-shaped UME. However, the kinetically controlled nucleation processes on that kind of UME have not yet received attention.

In this sense, the objective of this work is to study the multiple electrocrystallization of $\mathrm{Ni}$ on a disk-shaped $\mathrm{Pt}$ UME (diameter of $40 \mu \mathrm{m}$ ) from a modified Watts bath, in order to verify the applicability of the conventional Abyaneh model to this kinetically controlled process on a very small substrate.

\section{Experimental}

A two-electrode polarographic Pyrex ${ }^{\circledR}$ cell (with an approximate volume of $25 \mathrm{~mL}$ ) was used to perform the experiments. This cell had a Teflon ${ }^{\circledR}$ cover with appropriate holes to hold a calomel system as the reference electrode, 
wich also served as the secondary electrode, the working electrode, and the deaeration facility.

All potentials quoted in this work were referred to the hydrogen reference electrode $(-0.241 \mathrm{~V} v s$. saturated calomel electrode ${ }^{22}$ ).

The working UME was obtained by sealing a Pt wire $(\phi=40 \mu \mathrm{m})$ in a Pyrex ${ }^{\circledR}$ tube and polishing the tip with a 1500 grid emery paper in order to expose the cross section in the shape of a micro-disk. The electrode prepared following this method presented a geometric area of $1.310^{-5}$ $\mathrm{cm}^{2}$. The real area of this electrode was evaluated as 4.0 $10^{-5} \mathrm{~cm}^{2}$ by cyclic voltammetry in $0.5 \mathrm{M} \mathrm{NaOH}$ solutions through the integration of the $\mathrm{H}$-adsorption peaks ${ }^{23,24}$.

The electrolytic bath consisted of a modification of the conventional Watts bath, and contained $330 \mathrm{~g} \mathrm{~L}^{-1}$ $\mathrm{NiSO}_{4} \cdot 6 \mathrm{H}_{2} \mathrm{O}+45 \mathrm{~g} \mathrm{~L}^{-1} \mathrm{Ni}\left(\mathrm{NO}_{3}\right)_{2} \cdot 6 \mathrm{H}_{2} \mathrm{O}+37 \mathrm{~g} \mathrm{~L}^{-1} \mathrm{H}_{3} \mathrm{BO}_{3}$. The contributions of the hydrogen evolution reaction to the total measured currents were evaluated from experiments in an equivalent bath whose $\mathrm{Ni}^{2+}$ salts were replaced by $\mathrm{Na}^{+}$ ones. All reagents were Merck P.A., and the water was purified by a Milli-Q system from Millipore. Before each experiment the electrolyte was deaerated by bubbling $\mathrm{N}_{2}$ (White Martins, SS) for $15 \mathrm{~min}$.

The electrochemical experiments were performed with a EG\&G PARC model 273 potentiostat-galvanostat linked to a 386 PC microcomputer through a GPIB interface. The software used to control the experiments was the M270 from EG\&G PARC.

\section{Results and Discussion}

The electrocrystallization of $\mathrm{Ni}$ on a disk-shaped $\mathrm{Pt}$ UME was studied by chronoamperometry. In order to establish the range of potentials for performing the potentiostatic jumps, cyclic voltammetric experiments were initially carried out in the electrolytic solution between 1.0 and $-1.0 \mathrm{~V}$ at $0.1 \mathrm{~V} \mathrm{~s}^{-1}$. The voltammetric response presents the cross-over of the anodic and cathodic branches, characteristic of the nucleation process, at a potential value near $-0.5 \mathrm{~V}$. This phenomenon is a consequence of the surface area increasing due to metal electrodeposition. Also, the voltammogram shows that it is difficult to promote the redissolution of the deposited $\mathrm{Ni}$ layer under the experimental conditions used. Therefore, the electrode surface had to be polished before each chronoamperometric experiment. An example of this voltammogram is shown in Fig. 2. From these preliminary voltammetric experiments a potential range from -0.57 to $-0.63 \mathrm{~V}$ was established for use in the $\mathrm{Ni}$ electrocrystallization studies. Thus, the potential jumps were performed from $0.94 \mathrm{~V}$ to the set of values specified in fig. 3.

The current transients obtained from the chronoamperometric experiments are displayed in Fig. 3.

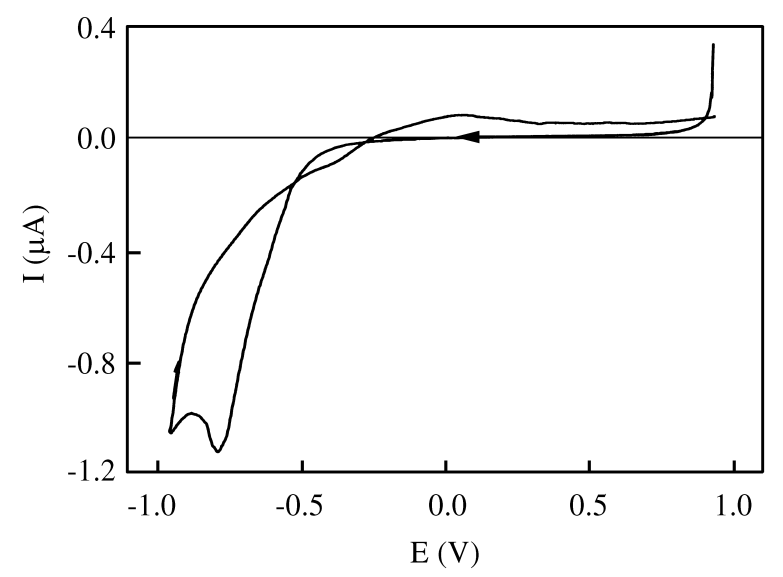

Figure 2. A cyclic voltammogram on Pt UME in a modified Watts bath. $\mathrm{v}=100 \mathrm{mV} \mathrm{s}^{-1}$

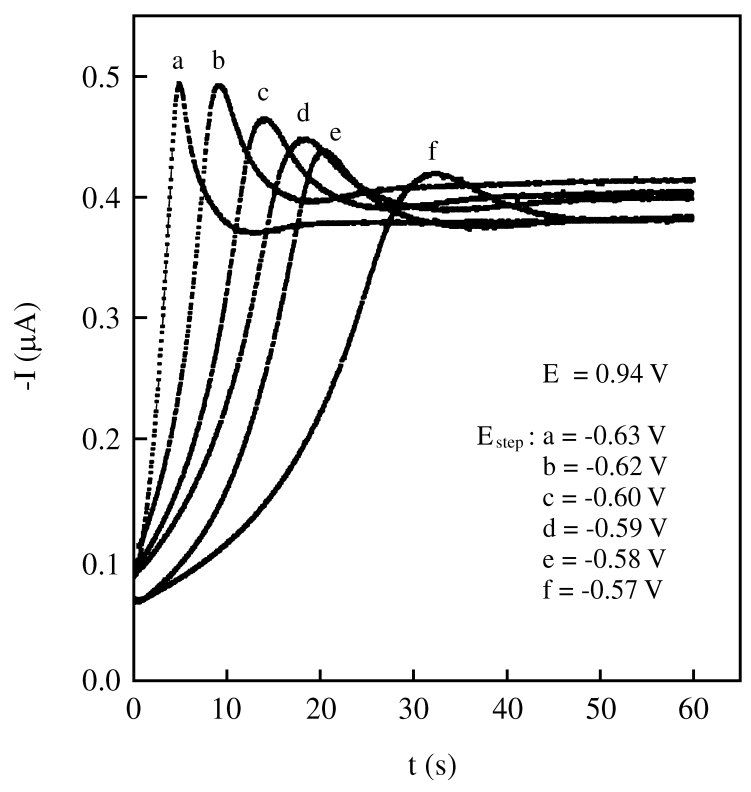

Figure 3. Potentiostatic transients for Ni electrocrystallization on a Pt UME.

The currents of the rising part of the transient prior to the maximum, corrected for the real area of the Pt substrate, were plotted against several functions of $\mathrm{t}\left(\mathrm{t}^{1 / 2}, \mathrm{t}^{3 / 2}, \mathrm{t}^{2}\right.$ and $\mathrm{t}^{3}$ ) as diagnostic criteria ${ }^{5,16}$. The excellent linear relationships of $\mathrm{I}_{\text {to }} \mathrm{t}^{2}$ are shown in Fig. 4, thus indicating an instantaneous 3D nucleation and growth process under kinetic control. This conclusion is supported by the results of Amblard et al. ${ }^{25}$, whose transmission electron micrographs for several times during the transient showed a constant number of nuclei growing until overlap, thus confirming instantaneous nucleation. Moreover, the micrographs also revealed that nuclei do not have perfect hemisphere shape, but resemble a "spherical cap" geometry.

As already discussed in the Introduction, a model taking these special characteristics of $\mathrm{Ni}$ electrodeposition 
into account was developed by Abyaneh and Fleischmann $^{12-14}$ and Abyaneh ${ }^{15,16}$. As such, Eqs. 1, 2 and 4 can be used to describe the transients obtained here. This model considers the nuclei to be spherical caps with different values for the contact angle, as defined by the different $\mathrm{k}$ and $\mathrm{k}$ ' rate constant values.

The values of $\theta, k^{\prime}, k$ and $N_{0}$ can be calculated from the experimental current transients displayed in Fig. 3 using the following relationship derived from Abyaneh's model $^{16}$ :

$$
\mathrm{P}_{i} t^{2}=\tau^{2}
$$

where

$$
\mathrm{P}_{i}=\frac{\pi M^{2} k^{2} N_{0}}{\rho^{2}}
$$

and $^{26}$

$$
\varepsilon^{2}=\left(\frac{k^{\prime}}{k}\right)=\frac{1-\cos \theta}{1+\cos \theta}
$$

where $\varepsilon$ is the eccentricity of the nucleus.

Since Equation (6) stands for the maximum in the current transients,

$$
\mathrm{P}_{i}=\left(\frac{\tau_{\max }}{t_{\max }}\right)^{2}
$$

using the experimental values of $t_{\max }$ and obtaining $\tau_{\max }$ from Table 1 of Ref. 16, it is possible to calculate $P_{i}$ for each transient. $\tau_{\max }$ is the non-dimensional parameter for time, depending on the contact angle. In this sense, for $\theta>50 \mathrm{de}-$ grees, $\tau_{\max }=1.6$, while for $\theta \leq 50$ degrees, $\tau_{\max }=1.8$. So, it is possible to evaluate $P_{i}$, assuming, $\tau_{\max }=1.6$ at first, and, if $\theta$ results in less than 50 degrees, changing the $\tau_{\max }$ value to 1.8 and recalculating $\mathrm{P}_{\mathrm{i}}$. Such approximations clearly simplify the task of calculating the various parameters of Abyaneh's model.

Equations 1, 2, and 7 imply that the linear relationships of i vs. $\mathrm{t}^{2}$ shown in Fig. 4 should present slopes given by

$$
\text { slope } \cong \frac{2+\cos \theta}{1+\cos \theta} i_{\infty} P_{i}
$$

where $\mathrm{i}_{\infty}$ is the limiting current density, corrected by the electrochemical area of the totally $\mathrm{Ni}$-covered electrode ( $1.47 \times 10^{-4} \mathrm{~cm}^{2}$, as calculated by cyclic voltammetric experiments in the $\alpha-\mathrm{Ni}(\mathrm{OH})_{2}$ potential region $\left.{ }^{27}\right)$ and by the hydrogen evolution reaction contribution. Therefore, Eq. 10 is useful for calculating the value of $\theta$ for each transient. The values of $i_{\infty}$ are easily obtained from the transients displayed in Fig. 3. These values must be corrected for the limiting currents due to the hydrogen evolution reaction obtained from distinct transients performed on a totally covered electrode surface in a $\mathrm{Ni}^{2+}$-free electrolyte. The corrected values of $i_{\infty}$ are shown in Table 1 and used to calculate $\theta$ for each transient. Table 1 also shows the step potentials, slopes, $\mathrm{P}_{\mathrm{i}}$, contact angles, and eccentricities $(\varepsilon)$ for each curve. The slopes and $\mathrm{P}_{\mathrm{i}}$ values are dictated by the variation of either the number of nuclei (which increases with potential) or the time for the maximum (which diminishes with potential) in the transients, as depicted by Eqs. 1 and 9.

The variation of $\theta$ with the step potential deserves special attention. As $\theta \rightarrow 90^{\circ}$, the shape of the nuclei approaches to a hemisphere (and $\varepsilon \rightarrow 1$ ). This situation is achieved when both growth rates, in the perpendicular and parallel directions have the same value. At low values of step potentials, the rate constant in the parallel direction should be greater than in the perpendicular one. This difference generates spherical caps with low values of $\varepsilon$ and $\theta$. This suggests that the variation of the rate constant in the parallel direction with potential is smaller than that in the perpendicular direction. In this case, the rising of the polarization values tends to equalize the velocities, thus increasing the contact angle. This behavior will be further analyzed below.

The values for k' were directly obtained from the limiting current of each transient using Eq. 2. The introduction

\begin{tabular}{|c|c|c|c|c|c|}
\hline$-E \mathrm{~V}$ & slope $x 10^{6} \mathrm{~A} \mathrm{~s}^{-2}$ & $\mathrm{I}_{\infty} \times 10^{6} \mathrm{~A}$ & $\mathrm{P}_{\mathrm{i}} \times 10^{3}$ & $\theta$ & $\varepsilon$ \\
\hline 0.57 & 0.00036 & 0.35 & 2.45 & 27.5 & 0.24 \\
\hline 0.58 & 0.00096 & 0.34 & 6.14 & 61.9 & 0.60 \\
\hline 0.59 & 0.0012 & 0.35 & 7.44 & 65.9 & 0.65 \\
\hline 0.60 & 0.0021 & 0.35 & 12.90 & 67.1 & 0.66 \\
\hline 0.62 & 0.0053 & 0.35 & 30.60 & 74.6 & 0.76 \\
\hline 0.63 & 0.017 & 0.33 & 98.80 & 87.6 & 0.96 \\
\hline
\end{tabular}
of parameters k' and $\theta$ in Eq. 8 allows the calculation of $\mathrm{k}$. Using Eq. 1 the number of nuclei was determined from the slope of each straight line shown in Fig. 4. The results of the

Table 1. The nucleation parameters involved in the calculation of $\theta$. 
Table 2. The kinetic parameters for the transients.

\begin{tabular}{cccccc}
\hline$-\mathrm{E} \mathrm{V}$ & $\mathrm{I}_{\max } \times 10^{6} \mathrm{~A}$ & $\mathrm{t}_{\max } \mathrm{s}$ & $\mathrm{k}^{\prime} \times 10^{7} \mathrm{~mol} \mathrm{~cm}^{-2} \mathrm{~s}^{-1}$ & $\mathrm{kx} 10^{7} \mathrm{~mol} \mathrm{~cm}^{-2} \mathrm{~s}^{-1}$ & $\mathrm{~N}_{0} \times 10^{-7} \mathrm{~cm}^{-2}$ \\
\hline 0.57 & 0.42 & 32.30 & 1.44 & 5.97 & 0.43 \\
0.58 & 0.44 & 20.42 & 1.40 & 2.33 & 7.06 \\
0.59 & 0.45 & 18.55 & 1.44 & 2.23 & 9.38 \\
0.60 & 0.47 & 14.06 & 1.44 & 2.17 & 17.18 \\
0.62 & 0.49 & 9.15 & 1.44 & 1.90 & 53.47 \\
0.63 & 0.50 & 5.09 & 1.36 & 1.42 & 305.63 \\
\hline
\end{tabular}

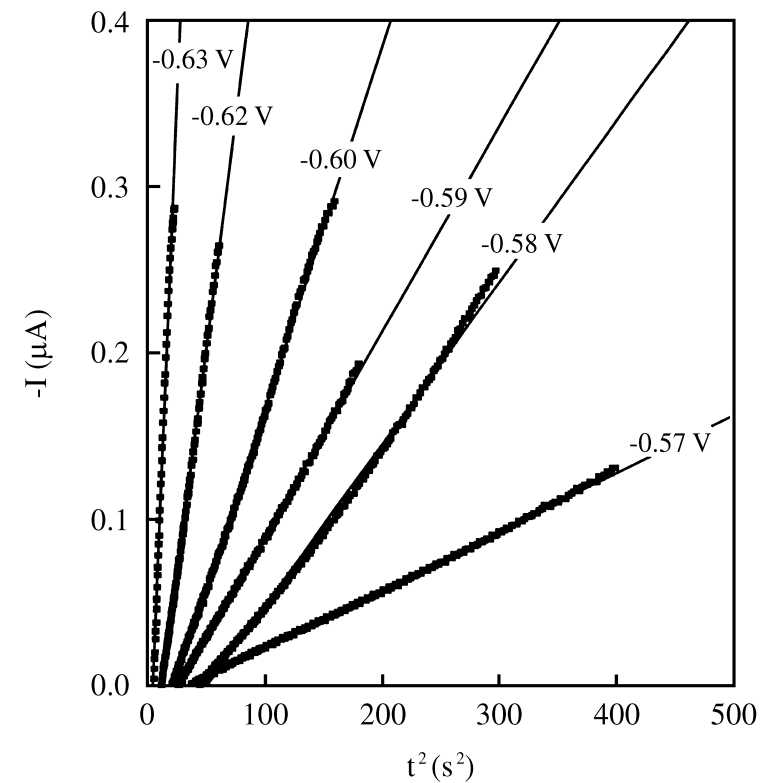

Figure 4. The linear dependence of I $v s$. $\mathrm{t}^{2}$ for the rising part of the transients for Ni electrocrystallization on a Pt UME.

calculations are presented in Table 2 together with the step potentials and the values of $\mathrm{I}_{\max }, \mathrm{t}_{\max }$, and $\mathrm{N}_{0}$. The various $\mathrm{I}_{\max } / \mathrm{I}_{\infty}$ relationships are greater than 1.218 , as postulated in Abyaneh's model ${ }^{16}$, which may account for the pronounced maxima in the transients.

An important analysis to be made from Table 2 is the dependence of the rate constant on the potential. The rate constant in the parallel direction (k) is strongly inhibited by increases in the step potential. This highly unexpected result may be explained by the hydrogen co-evolution on bare Pt surfaces in this cathodic potential range. The occupation rate of the surface active sites by adsorbed $\mathrm{H}$ (which increases with the cathodic potential) may make the growth of nuclei in the parallel direction difficult. Another possibility is related to the increasing number of nuclei on such a small electrode surface, which will be discussed below. Moreover, the values of k' are independent of the potential, an expected result because they are obtained directly from the limiting diffusional current values (Eq. 2) which are not dependent on the potential. The small variations observed in the k' values with the step potentials might be a consequence of alterations in the limiting currents caused by changes in the surface area, which can even extrapolate the boundaries of the substrate ${ }^{19}$. The determined values of $\mathrm{k}$ and k' are in close agreement with the assumptions made above to explain the values reported in Table 1, i.e., the influence of the step potentials on the geometry of the nuclei.

Finally, the number of nuclei greatly increases with the cathodic potential. Although this is normal behavior in instantaneous nucleation, it can bring about dramatic consequences in the parallel rate constants. The large number of nuclei $(40,000$ at the most cathodic potential) could promote inhibition zones that diminish the growth rates in the parallel direction.

\section{Conclusions}

This work reports for the first time, to the authors' knowledge, experimental results from $\mathrm{Ni}$ electrocrystallization on Pt UMEs. This is also one of the few examples of experimental applications of Abyaneh's model. The values obtained seem to indicate that Abyaneh's model may be applied to such small electrodes. This convenient behavior is related to the kinetic control in $\mathrm{Ni}$ nucleation and growth, since the traditional models are inaccurate to describing diffusion-controlled processes on UMEs. In this case, proper diffusion-controlled equations had to be developed ${ }^{21}$.

The calculated contact angles showed that nuclei grow in a spherical cap geometry. This was fully confirmed by the distinct values of the rate constants related to the growth of the nuclei in the perpendicular and parallel directions in relation to the surface, as well as their dependence on the step potential. The interpretation of this phenomenon is completely based on Abyaneh's model.

The co-evolution of hydrogen, first on $\mathrm{Pt}$ and then on $\mathrm{Ni}$ surfaces, also plays an important role in the transient shapes and deserves special attention. Nevertheless, it is possible to evaluate its contribution and subtract it from the $\mathrm{Ni}$ electrocrystallization response.

The correct evaluation of electrochemical active areas is also very important because in the ascendant branch of the transients the substrate was smooth platinum, replaced 
by electrodeposited nickel in the limiting currents region. Both surfaces require appropriate methods to evaluate the electrochemical areas.

Finally, the large number of nuclei deposited on the small electrode surface may promote an inhibitory effect on the rate constants for parallel growth. The formation of such a large number of nuclei is related to the interactions between platinum and nickel.

\section{Acknowledgments}

The authors wish to thank CNPq for the student and research grants.

\section{References}

1. Gunawardena, G.A.; Hills, G.J.; Montenegro, I. Electrochim. Acta 1978, 23, 693.

2. Gunawardena, G.A.; Hills, G.J.; Montenegro, I.; Scharifker, B.R. J. Electroanal. Chem. 1982, 138, 225.

3. Gunawardena, G.A.; Hills, G.J.; Montenegro, I. J. Electroanal. Chem. 1982, 138, 241.

4. Gunawardena, G.A.; Hills, G.J.; Montenegro, I.; Scharifker, B.R. J. Electroanal. Chem. 1982, 138, 255.

5. Scharifker, B.R.; Hills, G.J. Electrochim. Acta 1983, $28,879$.

6. Scharifker, B.R.; Mostany, J. J. Electroanal. Chem. 1984, 177, 13.

7. Mostany, J.; Mozota, J.; Scharifker, B.R. J. Electroanal. Chem. 1984, 177, 25.

8. Serruya, A.; Mostany, J.; Scharifker, B.R. J. Chem. Soc. Faraday Trans. 1993, 89, 255.

9. Mostany, J.; Serruya, A.; Scharifker, B.R. J. Electroanal. Chem. 1995, 383, 37.

10. Milchev, A.; Vassileva, E.; Kertov, V. J. Electroanal. Chem. 1980, 107, 323.
11. Milchev, A.; Vassileva, E. J. Electroanal. Chem. 1980, 107, 337.

12. Abyaneh, M.Y.; Fleischmann, M. J. Electroanal. Chem. 1981, 119, 187.

13. Abyaneh, M.Y.; Fleischmann, M. J. Electroanal. Chem. 1981, 119, 197.

14. Abyaneh, M.Y.; Fleischmann, M. Electrochim. Acta 1982, 10, 1513.

15. Abyaneh, M.Y. Electrochim. Acta 1982, 9, 1329.

16. Abyaneh, M.Y. J. Electroanal. Chem. 1986, 209, 1.

17. Hills, G.; Pour, A.K.; Scharifker, B.R. Electrochim. Acta 1983, 28, 892.

18. Montenegro, M.I. Portugalia Electrochim. Acta 1985, 3, 165.

19. Scharifker, B.R. In Modern Aspects of Electrochemistry, vol. 22 : Bockris, J. O'M.; Conway, B.E.; White, R.E. Eds.; Plenum Press; New York, 1992, p. 467.

20. Correia, A.N.; Mascaro, L.H.; Machado, S.A.S.; Mazo, L.H.; Avaca, L.A. Química Nova 1995, 18, 475.

21. Correia, A.N.; Machado; S.A.S.; Sampaio, J.C.V.; Avaca, L.A. J. Electroanal. Chem. 1996, 407, 37.

22. Bard, A.J.; Faulkner, L.R. In Electrochemical Methods, Fundamentals and Applications; John Wiley \& Sons; New York, 1980.

23. Woods, R. In Advances in Electroanalytical Chemistry, vol. 9; Bard, A.J., Ed.; Marcel Dekker; New York, 1976.

24. Machado, S.A.S. PhD Thesis, IFQSC-USP, Brazil, 1989.

25. Amblard, J.; Froment, M.; Maurin, G.; Mercier, D.; Trevisan-Souteyrand, E. J. Electroanal. Chem. 1982, $134,345$.

26. Abyaneh, M.Y. J. Electrochem. Soc. 1991, 138, 2491.

27. Machado, S.A.S.; Avaca, L.A. Electrochim. Acta 1994, 39, 1385. 